\title{
PENGARUH MEDIA PEMBELAJARAN DAN KECERDASAN EMOSIONAL TERHADAP HASIL BELAJAR SISWA SEKOLAH MENENGAH KEJURUAN
}

\author{
Didik Rohmantoro ${ }^{1}$, Sapitri Januariyansah ${ }^{2}$, Dwiki Muda Yulanto ${ }^{3}$. \\ ${ }^{1}$ Fakultas Keguruan dan Ilmu Pendidikan, Universitas PGRI Yogyakarta, Indonesia. \\ Email: didikrohmantoro@gmail.com \\ ${ }^{2}$ Fakultas Teknik, Universitas Negeri Medan, Indonesia. \\ ${ }^{3}$ Fakultas Teknik, Universitas Negeri Medan, Indonesia.
}

\begin{abstract}
ABSTRAK
Penelitian ini bertujuan untuk menganalisis seberapa besar pengaruh media pembelajaran dan kecerdasan emosional terhadap hasil belajar siswa. Penelitian ini merupakan penelitian ex-post facto jenis correlational study dengan pendekatan kuantitatif. Teknik sampel menggunakan teknik Slovin dengan probabilitas random sampling. Teknik pengumpulan data menggunakan kuesioner dan dokumentasi. Validitas instrument menggunakan expert judgment dan uji coba lapangan. Reliabilitas menggunakan teknik cronbach's alpha. Teknik analisis data menggunakan statistik inferensial. Hasil penelitian menunjukkan bahwa terdapat pengaruh yang positif dan signifikan antara (1) $\mathrm{X}_{1}$ terhadap $\mathrm{Y}$ dengan nilai $\mathrm{R}=0,279$ (rendah) dan $\mathrm{R}^{2}=0,078$; (2) $\mathrm{X}_{2}$ terhadap $\mathrm{Y}$ dengan nilai $\mathrm{R}=0,546$ (sedang) dan $\mathrm{R}^{2}=0,299$ dan; (3) $\mathrm{X}_{1}$ dan $\mathrm{X}_{2}$ terhadap $\mathrm{Y}$ dengan nilai $\mathrm{R}=0,592$ (sedang) dan $\mathrm{R}_{2}=$ 0,351 dengan persamaan regresi $\mathrm{Y}=2,971+0,001 \mathrm{X}_{1}+0,003 \mathrm{X}_{2}$. Pada penelitian ini media pembelajaran dan kecerdasan emosional memberikan sumbangan yang kecil. Namun, pembentukan keduanya penting untuk bekal siswa setelah lulus.
\end{abstract}

Kata kunci: media pembelajaran, kecerdasan emosional, hasil belajar.

\begin{abstract}
This study aims to analyze the extent of the influence of learning media and emotional intelligence on student learning outcomes. This research was an ex-post facto type correlational study with a quantitative approach. The sample technique used the Solvin technique with random sampling probability. Data collection techniques used questionnaires and documentation. The validity of the instrument used expert judgment and field trials. Reliability used the cronbach's alpha technique. Data analysis techniques used inferential statistics. The results showed that there was a positive and significant effect between (1) $\mathrm{X} 1$ against $\mathrm{Y}$ with a value of $\mathrm{R}=0.279$ (low) and $\mathrm{R} 2=0.078$; (2) $\mathrm{X} 2$ with respect to $\mathrm{Y}$ with values $\mathrm{R}=0.546$ (moderate) and $\mathrm{R} 2=0.299$ and; (3) $\mathrm{X} 1$ and $\mathrm{X} 2$ with respect to $\mathrm{Y}$ with the value of $\mathrm{R}=0.592$ (moderate) and $\mathrm{R} 2=0.351$ with the regression equation $\mathrm{Y}=2.971+0.001 \mathrm{X} 1+$ $0.003 X 2$. In this study learning media and emotional intelligence make a small contribution. However, the formation of both of them is important for students after graduation.
\end{abstract}

Keywords: learning media, emotional intelligence, learning outcomes. 


\section{Journal of Automotive Technology Vocational Education}

Volume 1, No 1, April 2020

Online: http://ojs.upy.ac.id/ojs/index.php/jatve

\section{PENDAHULUAN}

Belajar adalah suatu kegiatan atau proses yang dialami oleh individu sebagai hasil dari pengalaman atau latihan untuk memperoleh suatu perubahan baik pada pengetahuan, pemahaman, keterampilan, dan nilai sikap, maupun motivasi (Sumardi Suryabrata, 1998; Gagne, 1977; Nana sudjana, 1989).

Proses belajar yang baik ditunjukkan dengan drajat pengukuran dari hasil belajar yang baik. Sudjana (2005: 22) mengatakan bahwa hasil belajar adalah kemampuankemampuan yang dimiliki oleh siswa setelah menerima pengalaman belajar. Bloom menjelaskan hasil belajar dicapai melalui tiga kategori yaitu (1) ranah kognitif yaitu berkenaan dengan hasil belajar intelektual yang terdiri dari pengetahuan, pemahaman, penerapan, dan penilaian; (2) ranah afektif yaitu berhubungan dengan perhatian, sikap, penghargaan, nilai, perasaan dan emosi dan; (3) ranah psikomotor yaitu meliputi keterampilan motorik (Dimyati dan Mujiono, 2006: 201). Jadi hasil belajar adalah tingkatan pengetahuan yang dicapai seseorang terhadap materi yang diterima ketika mengikuti dan mengerjakan tugas dan kegiatan pembelajaran.

Dalam kegiatan pembelajaran dibutuhkan media yang dapat menyampaikan pesan dari pendidik kepada peserta didik. Media tersebut disebut dengan media pembelajaran. Briggs mengemukakan bahwa media pembelajaran merupakan sarana fisik yang digunakan untuk menyampaikan isi/materi pelajaran yang dapat berupa buku, film, video, slide, dan sebagainya. (Rudi dan Cepi, 2008: 6). Media pembelajaran juga merupakan segala bentuk sesuatu yang dapat menyampaikan pesan dari pengirim ke penerima (Sadiman, 2008: 7). Pentingnya media pembelajaran bahwa pemakaian media pembelajaran dalam proses belajar dapat membangkitkan minat, motivasi, dan rangsangan kegiatan belajar bahkan memberikan pengaruh psikologis pada peserta didik dan meningkatnya minat dan motivasi belajar siswa sehingga mempermudah guru menyampaikan materi pembelajaran.

Pendidikan di sekolah bukan hanya perlu mengembangkan rational intelligence yaitu model pemahaman yang dipahami siswa saja, melainkan juga perlu mengembangkan emotional intelligence siswa. Proses belajar di sekolah adalah proses yang sifatnya kompleks dan menyeluruh sehingga IQ tidak dapat berfungsi dengan baik tanpa partisipasi penghayatan emosional terhadap mata pelajaran yang disampaikan dan juga IQ dan emotional quotient (EQ) memiliki sifat saling melengkapi. Keseimbangan antara IQ dan EQ merupakan kunci keberhasilan belajar siswa di sekolah (Goleman, 2002). Kecerdasan emosional atau emotional quotient (EQ) adalah kemampuan mengenali perasaan sendiri dan perasaan orang lain, kemampuan memotivasi diri sendiri, kemampuan mengolah emosi dengan baik pada diri sendiri dan orang lain (Goleman, 2002).

Kecerdasan intelektual (IQ) hanya menyumbang $20 \%$ bagi kesuksesan, sedangkan $80 \%$ adalah sumbangan faktor kekuatan-kekuatan lain, diantaranya adalah kecerdasan emosional atau Emotional Quotient (EQ). Pada dasarnya EQ merupakan hal yang relatif baru dibandingkan IQ, namun beberapa penelitian telah mengisyaratkan bahwa kecerdasan emosional tidak kalah penting dengan IQ (Goleman, 2002: 44).

Hasil observasi di SMK Pembangunan Nasional Purwodadi pada kelas X jurusan Teknik Sepeda Motor (TSM) diperoleh bahwa hasil belajar siswa belum maksimal. Hal ini terlihat dari rata-rata nilai rapor semester ganjil tahun pelajaran 2014/2015 yang masih jauh di bawah ratarata yang ditetapkan Sekolah. Berdasarkan 
hasil observasi tidak tercapainya nilai ratarata siswa pada standar yang ditetapkan diperkirakan pada saat proses pembelajaran siswa masih kurang memiliki rasa percaya diri. Hal ini terlihat dari tidak ada respon siswa untuk bertanya saat diperintahkan oleh guru. Saat pembelajaran, kerja sama antar siswa relative pasif yang berarti belum terbangun dengan baik. Kedisiplinan siswa juga masih kurang terlihat dari kebiasaan siswa dating terlambat ke sekolah dan ke dalam kelas. Sehingga dapat disimpulkan bahwa hasil belajar siswa kurang baik.

Berdasarkan uraian di atas, rendahnya hasil belajar siswa disebabkan rendahnya motivasi siswa dalam belajar, ketidakdisiplinan siswa, serta faktor lain seperti siswa memiliki kerja sama tim yang belum terbangun dengan baik. Melalui penggunaan media pembelajaran dan pembentukan kecerdasan emosional siswa, Hasil belajar siswa diperkirakan dapat meningkat. Oleh sebab itu, penelitian ini bertujuan untuk menganalisis pengaruh media pembelajaran (X1) dan kecerdasan emosional (X2) terhadap hasil belajar (Y) siswa sekolah menengah kejuruan. Penelitian ini penting untuk dilakukan agar guru dan sekolah dapat mengetahui dan kemudian dapat mengevaluasi kembali kegiatan pembelajaran agar ke depan kepribadian dan hasil belajar siswa menjadi lebih baik.

\section{METODE PENELITIAN}

Penelitian ini merupakan penelitian ex-post facto jenis correlational study dengan pendekatan kuantitatif. Populasi dalam penelitian ini adalah seluruh siswa kelas $\mathrm{X}$ TSM SMK Pembangunan Nasional Purwodadi. Berdasarkan data yang diperoleh dari pihak sekolah, jumlah populasi kelas $\mathrm{X}$ TSM SMK Pembangunan Nasional Purwodadi adalah 117. terbagi dalam 3 kelas, yaitu kelas X TSM 01 berjumlah 40, kelas X TSM 02 berjumlah 40, kelas X TSM 03 berjumlah 37.
Pada penelitian ini penentuan ukuran jumlah sampel menggunakan rumus Slovin Probabilitas Random Sampling. Jumlah sampel yang digunakan dalam penelitian ini adalah 91 siswa di kelas X TSM SMK Pembangunan Nasional Purwodadi.

Pengumpulan data dalam penelitian ini menggunakan sumber primer dan sekunder. Data primer diperoleh menggunakan Instrumen yang berupa angket (kuesioner). Sedangkan data sekunder menggunakan dokumentasi.

Teknik validitas instrument menggunakan validitas teoretis dan validitas empiris. Validitas teoretis menggunakan expert judgment. Sedangkan validitas empiris dilakukan dengan mengujicobakan instrument ke lapangan. Reliabilitas instrument menggunakan teknik cronbach's alpha.

Teknik analisis data menggunakan teknik analisis inferensial yaitu dengan menguji hipotesis. Jenis analisis hipotesis dapat berupa parametris dan non parametris. Hal ini ditentukan dengan hasil uji prasyarat analisis yaitu uji normalitas, uji linieritas, dan uji multikolinieritas.

\section{HASIL DAN PEMBAHASAN}

\section{A. HASIL}

Terdapat 3 bentuk hipotesis yag akan diujikan yaitu:

1. H1: ada pengaruh yang positif dan signifikan antara media pembelajaran (X1) terhadap Hasil Belajar (Y)

H0: Tidak ada pengaruh yang positif dan signifikan antara media pembelajaran (X1) terhadap Hasil Belajar (Y)

2. H1: ada pengaruh yang positif dan signifikan antara kecerdasan emosional (X2) terhadap Hasil Belajar (Y) H0: Tidak ada pengaruh yang positif dan signifikan antara kecerdasan emosional (X2) terhadap Hasil Belajar (Y)

3. H1: ada pengaruh yang positif dan signifikan antara media pembelajaran (x1) dan kecerdasan emosional (X2) secara 
bersama-sama terhadap Hasil Belajar (Y) H0: Tidak ada pengaruh yang positif dan signifikan antara media pembelajaran (X1) dan kecerdasan emosional (X2) secara bersama-sama terhadap Hasil Belajar (Y)

\section{Uji Prasyarat Analisis}

Uji hipotesis yang digunakan adalah dengan uji parametris dikarenakan uji asumsi klasik yaitu uji normalitas, uji linieritas, dan uji multikolinieritas telah terpenuhi berdasarkan Tabel 1, Tabel 2, dan Tabel 3.

Tabel 1. Uji Normalitas

\begin{tabular}{ccc}
\hline Variabel & $\begin{array}{c}\text { Sig. Kolmogorov- } \\
\text { Smirnov }\end{array}$ & Kesimpulan \\
\hline X1 & 0.089 & Normal \\
X2 & 0.230 & Normal \\
Y & 0.176 & Normal \\
\hline
\end{tabular}

Tabel 2. Uji Linieritas

\begin{tabular}{cccccc}
\hline $\begin{array}{c}\text { Autokorelasi } \\
\text { negative }\end{array}$ & $\begin{array}{c}\text { Tanpa } \\
\text { kesimpulan }\end{array}$ & $\begin{array}{c}\text { Tidak } \\
\text { terdapat } \\
\text { korelasi }\end{array}$ & $\begin{array}{c}\text { Tanpa } \\
\text { kesimpulan }\end{array}$ & $\begin{array}{c}\text { Autokorelasi } \\
\text { positif }\end{array}$ & Ket \\
\hline $\mathrm{dL}$ & $\mathrm{dU}$ & $\mathrm{DW}$ & $4-\mathrm{dU}$ & $4-\mathrm{dL}$ & Linier \\
1,61 & 1,70 & 1,56 & 1,56 & 1,75 & \\
\hline
\end{tabular}

Tabel 3. Uji Multikolinieritas

\begin{tabular}{cccc}
\hline \multirow{2}{*}{ Variabel } & \multicolumn{2}{c}{$\begin{array}{c}\text { Sollinearity } \\
\text { Statistics }\end{array}$} & Kesimpulan \\
\cline { 2 - 4 } & $\begin{array}{c}\text { Tolera } \\
\text { nce }\end{array}$ & VIF & \\
\hline X1 & 0,9911 & 1,009 & Tidak Multikolinieritas \\
X2 & 0,9911 & 1,009 & Tidak Multikolinieritas \\
\hline
\end{tabular}

\section{Uji Hipotesis}

\section{Hipotesis pertama dan kedua}

Berdasarkan Tabel 4 dapat disimpulkan bahwa hipotesis alternatif (H1) dari hipotesis pertama dan kedua diterima.

Tabel 4. Hasil uji hipotesis pertama dan kedua

\begin{tabular}{lllll}
\hline Variabel & $\mathbf{r}$ & $\mathbf{r}^{2}$ & $\begin{array}{r}\text { Sig } \\
(p)\end{array}$ & Ket \\
\hline
\end{tabular}

\begin{tabular}{|c|c|c|c|c|}
\hline $\mathrm{X}_{1}-\mathrm{Y}$ & 0,279 & 0,078 & 0,000 & $\begin{array}{c}\text { Positif } \\
\text { dan } \\
\text { Signifikan }\end{array}$ \\
\hline$X_{2}-Y$ & 0,546 & 0,299 & 0,000 & $\begin{array}{c}\text { Positif } \\
\text { dan } \\
\text { Signifikan }\end{array}$ \\
\hline
\end{tabular}

\section{Uji hipotesis ketiga}

Berdasarkan Tabel 5 dapat disimpulkan bahwa hipotesis alternatif (H1) dari hipotesis ketiga diterima.

Tabel 5. Hasil uji hipotesis ketiga

\begin{tabular}{ccccccc}
\hline Variabel & $\mathbf{r}$ & $\mathbf{r}^{2}$ & $\begin{array}{c}\text { Sig } \\
(\boldsymbol{p})\end{array}$ & Koef & Konst & Ket \\
\hline $\mathrm{X}_{12} \mathrm{Y}$ & 0,592 & 0,351 & 0,000 & $\begin{array}{c}\mathrm{X} 1=0,001 \\
\mathrm{X} 2=0,003\end{array}$ & 2.971 & $\begin{array}{c}\text { Positif } \\
\text { dan } \\
\text { Signifikan }\end{array}$ \\
\hline
\end{tabular}

\section{B. PEMBAHASAN}

\section{Pengaruh media pembelajaran $\left(X_{1}\right)$ terhadap hasil belajar (Y)}

Berdasarkan Tabel 4 diketahui bahwa koefisien korelasi antara $\mathrm{X}_{1}$ terhadap $\mathrm{Y}$ adalah sebesar 0,279 yang menunjukkan tingkat korelasi rendah. Koefisien korelasi bernilai positif yang berarti pengaruh $\mathrm{X}_{1}$ et terhadap $\mathrm{Y}$ adalah positif. Pengaruh yang terjadi dapat dikatakan signifikan karena nilai $\operatorname{sig}(\mathrm{p})$ yaitu sebesar $0,00<0,05$. Hasil analisis data menunjukkan terdapat pengaruh antar $\mathrm{X}_{1}$ terhadap $\mathrm{Y}$ hal ini dapat dilihat berdasarkan nilai koefisien determinasi sebesar 0,078 yang berarti variabel media pembelajaran memberikan pengaruh sebesar $7,8 \%$ terhadap hasil belajar sedangankan $92,2 \%$ dipengaruhi oleh faktor lain.

\section{Pengaruh kecerdasan emosional $\left(\mathbf{X}_{2}\right)$ terhadap hasil belajar (Y)}

Berdasarkan Tabel 4 diketahui bahwa koefisien korelasi antara $\mathrm{X}_{2}$ terhadap $\mathrm{Y}$ adalah sebesar 0,546 yang menunjukkan tingkat korelasi sedang. Koefisien korelasi bernilai positif yang berarti pengaruh $\mathrm{X}_{2}$ terhadap $\mathrm{Y}$ adalah positif. Pengaruh yang terjadi dapat dikatakan signifikan karena nilai sig (p) yaitu sebesar $0,00<0,05$. Hasil analisis data menunjukkan terdapat pengaruh 
antar $\mathrm{X}_{2}$ terhadap $\mathrm{Y}$ hal ini dapat dilihat berdasarkan nilai koefisien determinasi sebesar 0,299 yang berarti variabel kecerdasan emosional memberikan pengaruh sebesar 29,9\% terhadap hasil belajar sedangkan $70,1 \%$ dipengaruhi oleh faktor lain.

\section{Pengaruh media pembelajaran (X1) dan kecerdasan emosional (X2) terhadap hasil belajar (Y)}

Berdasarkan Tabel 5 diketahui bahwa koefisien korelasi antara $X_{1}$ dan $X_{2}$ terhadap $\mathrm{Y}$ adalah sebesar 0,592 yang menunjukkan tingkat korelasi sedang. Koefisien korelasi bernilai positif yang berarti pengaruh $X_{1}$ dan $\mathrm{X}_{2}$ terhadap $\mathrm{Y}$ adalah positif. Pengaruh yang terjadi dapat dikatakan signifikan karena nilai sig (p) yaitu sebesar $0,00<0,05$. Hasil analisis data menunjukkan terdapat pengaruh antar $\mathrm{X}_{1}$ dan $\mathrm{X}_{2}$ terhadap $\mathrm{Y}$ hal ini dapat dilihat berdasarkan nilai koefisien determinasi sebesar 0,351 yang berarti variabel media pembelajaran dan variabel kecerdasan emosional memberikan pengaruh sebesar $35,1 \%$ terhadap hasil belajar sedangkan $64,9 \%$ dipengaruhi oleh faktor lain.

Untuk memprediksi besaran nilai variabel $\mathrm{Y}$ melalui nilai variabel $\mathrm{X}_{1}$ dan variabel $\mathrm{X}_{2}$ dapat dilakukan dengan rumus $\mathrm{Y}$ $=2,971+0,001 X_{1}+0,003 X_{2}$ yang berarti jika $\mathrm{X}_{1}$ meningkat satu satuan maka $\mathrm{Y}$ akan meningkat sebesar 0,001 dan jika $\mathrm{X}_{2}$ meningkat satu satuan maka $X_{2}$ meningkat 0,003 .

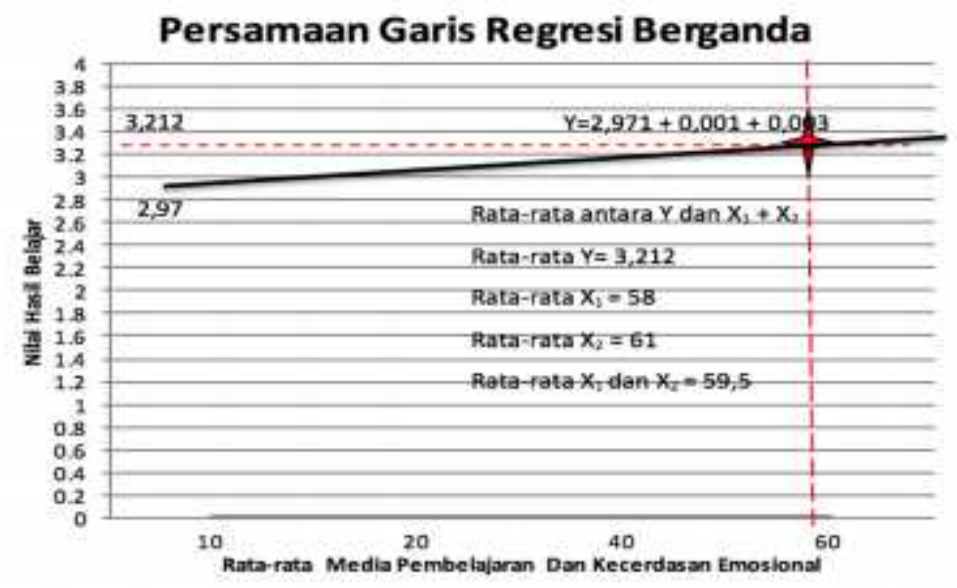

Gambar 1. Grafik regresi antar $X_{1}$ dan $X_{2}$ terhadap $Y$

Berdasakan hasil penelitian media pembelajaran dan kecerdasan emosional memiliki pengaruh positif dan signifikan terhadap hasil belajar. Namun, besar pengaruh yang terjadi tergolong kecil. Ratarata tingkat korelasi antara variabel $\mathrm{X}_{1}$ dan variabel $\mathrm{X}_{2}$ tergolong rendah dan sedang.

Pemanfaatan media pembelajaran sebenarnya dapat membantu pendidikan sebagaimana Sutjiono (2005) dalam penelitiannya menyimpulkan bahwa media pembelajaran sangat dibutuhkan oleh pendidik agar kegiatan belajar mengajar dapat berjalan secara efektif dan efisien. Penelitian lain yang dilakukan oleh Puspitasari dan Puspitarini \& Hanif (2019) bahwa siswa tidak tertarik dengan pembelajaran menggunakan cerama sehingga diperlukan media pembelajaran berbasis teknologi agar siswa termotivasi. Sehingga penggunaan media pembelajaran merupakan rekomendasi utama dalam proses pembelajaran. Penggunaan media pembelajaran digital juga dapat sebagai alternatif untuk generasi sekarang. Salah satu bentuk media pembelajaran yang 
diperkirakan dapat mengakomodasi generasi sekarang (generasi Z dan generasi Alpha) yaitu fasilitas digital classroom karena sesuai dengan karakteristik generasi Z dan Alpha yang akrab menggunakan teknologi digital, lebih menarik dan lebih fleksibel, dan bisa digunakan secara positif (untuk tujuan pembelajaran) di rumah (Januariyansah \& Rohmantoro, 2018).

Di sisi lain, kecerdasan emosional yang memberi pengaruh tidak besar dalam penelitian ini tetap perlu diperhatikan. Arora (2017) dalam penelitiannya menuturkan bahwa kecerdasan emosi sangat penting karena bisa membantu mendapatkan promosi. Kecerdasan emosional dua kali lebih penting daripada keterampilan analitis dan teknis. Kannaiah \& Shanthi (2015) dalam penelitiannya mengatakan bahwa kecerdasan emosional memainkan peranan penting bagi karyawan dalam organisasi di dunia kerja. Di dunia kerja, kecerdasan emosional dapat digunakan untuk mengelola proses perubahan diri sendiri dan orang lain (Issah, 2018).

\section{SIMPULAN}

Hasil belajar dapat ditingkatkan dengan meningkatkan penggunaan media pembelajaran dan kecerdasan emosional siswa. Namun, pada penelitian ini peningkatan hasil belajar melalui media pembelajaran dan kecerdasan emosional yang terjadi tidak terlalu besar. Pada dasarnya peningkatan penggunaan media pembelajaran merupakan hal yang wajib bagi guru karena dapat menjadikan pembelajaran lebih efektif dan efisien. Penggunaan media pembelajaran digital dianggap dapat mengakomodasi siswa saat ini. Di sisi lain, peningkatan kecerdasan emosional siswa dapat menjadi bekal bagi siswa SMK yang memiliki skill siap kerja. Melalui kecerdasan emosional siswa dapat mengembangkan karier yang baik dan dapat melakukan perilaku organisasi yang baik.

\section{DAFTAR PUSTAKA}

Arora, B. (2017). Importance Of Emotional Intelligence In The Workplace. International Journal of Engineering and Applied Sciences, 4 (1), pp. 4345.

Dimyati \& Mudjiono. (2006). Belajar dan Pembelajaran, Jakarta: Rineka Cipta.

Gagne, R.M. (1977). The conditions of learning.New York: Holt Rinehart and Winston.

Goleman, Daniel. (2002). Working With Emotional Intelligence (terjemahan). Jakarta : PT. Gramedia Pustaka Utama.

Issah, M. (2018). Change Leadership: The Role of Emotional Intelligence. SAGE Open, pp. 1-6.

Januariyansah, S \& Rohmantoro, D. (2018). The Role of Digital Classroom Facilities to Accommodate Learning Process ff The Z And Alpha Generations. Proceeding of International Conference On ChildFriendly Education, Muhammadiyah Surakarta University, pp. 434-439.

Kannaiah, D \& Shanthi, R. (2015). A Study on Emotional Intelligence At Work Place. European Journal of Business and Management, 7 (24), pp. 147154.

Nana Sudjana. (1989). Penilaian Hasil Proses Belajar Mengajar. Bandung : PT.Remaja Rosdakarya.

Nana, Sudjana. (2005). Penilaian Hasil

Proses Belajar Mengajar. Cetakan ketujuh. Bandung : PT Remaja Rosdakarya.

Puspitarini, Y. D \& Hanif, M. (2019). Using Learning Media to Increase Learning Motivation in Elementary School. Anatolian Journal of Education, 4 (2), pp. 53-60.

Rudi, S., \& Cepi, R. (2008). Media Pembelajaran. Bandung: Jurusan Kurtekpend FIP UPI. 
Journal of Automotive Technology Vocational Education

Vol. 01, No. 1, April 2020

Sudiman, A, S, dkk. (2008). Media

Pendidikan. Jakarta: PT. Raja

Grafindo Persada.

Sumadi, Suryabrata. (1998). Psikologi

Pendidikan. Jakarta : PT. Raja

Grafindo Persada.

Sutjiono T. W. A. (2005). Pendayagunaan

media pembelajaran. Jurnal

Pendidikan Penabur, 4 (4), pp. 76-84. 